\title{
Espacio y violencia: elementos para un esquema comprensivo ${ }^{1}$
}

\author{
Space and Violence: Elements for a Comprehensive Scheme
}

\author{
Fabián GonZÁLEz LunA \\ Facultad de Filosofía y Letras, \\ Universidad Nacional Autónoma de México \\ México
}

\section{Resumen}

Se plantea una aproximación geográfica a la violencia que trata de superar los enfoques centrados en los aspectos cuantitativos de las expresiones de la violencia directa para poder abordar sus condiciones y mecanismos de realización como una estructura-estructurante de la praxis social. El principal objetivo del artículo es desarrollar un esquema básico sobre la espacialización de la violencia a partir de la combinación de tres mecanismos: la valorización del espacio por medio de la acumulación por despojo, las rentas culturales y tecnológicas, y los dispositivos espaciales de control y disciplinamiento social. Estos mecanismos se articulan en una organización de formas y funciones espaciales que tienen un papel estratégico en la ordenación social dentro del proyecto neoliberal. Lo anterior se articula con la propuesta metodológica de la producción del espacio y la aproximación a la violencia en su dimensión estructural. Se argumenta que esta violencia implica la anulación social, ya sea por medio del desplazamiento o por eliminación de los recursos sociales, para producir espacios-tiempos homogéneos vacíos. Este esquema se pone en diálogo para abordar los espacios públicos en la ciudad neoliberal como la expresión contradictoria y conflictiva entre la espacialización de la violencia como ámbito de la representación del espacio y las contra-topologías del poder como espacios de representación.

Palabras clave: espacialización de la violencia, espacios vacíos homogéneos, neoliberalismo, espacio público

\footnotetext{
${ }^{1}$ Artículo realizado dentro de las actividades del proyecto de investigación PAPIIT IN305518 "Desarrollo geográfico desigual y violencia: un análisis a partir de la tematización”, por lo que se agradece a la DGAPA, UNAM, su apoyo a este proyecto.
} 


\begin{abstract}
This article proposes a geographical approach to violence to overcome the approaches focused on the quantitative aspects of direct violence expressions to address its conditions and mechanisms of realization as a structure-structuring of social praxis. The main objective of the article is to develop a basic scheme on the spatialization of violence, the realization of which is carried out from a combination of three mechanisms: the valorization of space through accumulation by dispossession, cultural and technological rents, and the spatial devices for social control and discipline. These mechanisms are articulated in an organization of spatial forms and functions with a strategic role in the neoliberal project of social order. The proposal to produce space and the approach to violence in its structural dimension is argued by realizing that violence implies an annulment, either through displacement or by eliminating social resources, to produce empty homogeneous times-spaces. This scheme is put into dialogue to address public spaces in the neoliberal city as the contradictory and conflictive expression between the spatialization of violence as a representation of space and the counter-topologies of power as spaces of representation.
\end{abstract}

Keyword: spatialization of violence, homogeneous empty spaces, neoliberalism, public space

\title{
Introducción
}

La violencia genera múltiples impactos en las diferentes dimensiones de la vida cotidiana individual y colectiva. Representa un fenómeno prioritario y es muy importante abordarlo e investigarlo desde diferentes propuestas teóricas y estrategias metodológicas, no sólo para tratar de comprender sus lógicas, efectos y manifestaciones, sino también para buscar la transformación de las realidades específicas que este fenómeno produce. En un plano general, puede existir la percepción de que todos compartimos el mismo sentido de la violencia y que existe una definición más o menos común; sin embargo, una mirada más atenta permite dar cuenta de que hay diversas maneras de entenderla y de vincularla con otros procesos y condiciones de la vida social.

La violencia como problema de investigación geográfica abre un amplio panorama de posibilidades analíticas, metodológicas y temáticas que pueden fortalecerse con la discusión teórica dentro de la disciplina y también contribuir en la construcción, ampliación y consolidación de diálogos y debates interdisciplinarios. La violencia es un fenómeno multidimensional y polisémico. No podemos asumirla como algo que todos entendemos de la misma forma, ni comprenderla desde la simple descripción empírica o desde perspectivas eclécticas. El desarrollo de la investigación sobre la violencia debe partir, necesariamente, de la discusión, confrontación y debate de las propuestas teóricas y de aproximación metodológica, lo que abordaremos en este trabajo. 
Se plantearán y desplegarán algunas herramientas analíticas para dar cuenta del papel que juega la violencia desde su dimensión espacial como eje estratégico del orden social y de sus formas de reproducción, es decir, como agencia histórica y geográfica en la praxis social. Al respecto, Harvey (2013) indica que una mirada geográfica a la estructura y organización espacial de la reproducción social dentro del desarrollo histórico del capitalismo permite, entre otras cosas, visibilizar el papel protagónico de la violencia como mediación que impone la lógica de la valorización del valor a la propia realización de la vida social. Así, esta mirada se dirige hacia la reflexión epistemológica para develar y comprender la racionalidad que sostiene e instrumentaliza a la violencia en la praxis social.

En esta dirección, el principal objetivo del artículo es exponer y desarrollar un andamiaje conceptual sobre la dimensión espacial de la violencia dentro del capitalismo tardío como agencia estratégica de acumulación y de ordenación de clase. Para lo anterior, se busca desarrollar algunos argumentos que aporten la articulación del esquema comprensivo sobre la espacialización de la violencia en la racionalidad urbana neoliberal, con énfasis en los espacios públicos. No se pretende presentar un panorama general sobre las expresiones de la violencia en la ciudad y sus espacios públicos; más bien la atención se centra en poner a debate una perspectiva geográfica que permita aprehender la lógica de la estructuración de la violencia en la espacialización, lo cual puede abrir caminos comprensivos para contribuir en los fundamentos de la violencia neoliberal. Para lograr lo anterior, el artículo se divide en cuatro apartados. En el primero se presenta el marco general de delimitación del problema de investigación respecto a la violencia; en el segundo se aborda la producción de espacio y la violencia estructural como pilares del esquema comprensivo de los espacios de violencia, mismo que se plantea de forma sintética en el tercer apartado. Por último, en el cuarto apartado el esquema se pone en movimiento para dialogar e interpelar a la ciudad neoliberal y sus espacios públicos.

\section{Delimitación del problema de investigación: violencia, ciudad neoliberal y geografía}

De acuerdo con Adolfo Sánchez Vázquez (2003), la violencia ha estado siempre presente en la historia de la humanidad, pero no significa que ésta defina la propia historia, ni se trata de una agencia universal, ni absoluta; más bien, la violencia es una mediación resultante de condiciones históricas y geográficas específicas. Los fundamentos de la violencia neoliberal no son diferentes a los de la modernidad capitalista (Echeverría, 2010). Las características particulares de la violencia se asocian con aquellas formas en que se realiza y el sentido que adquieren en el contexto histórico geográfico concreto de su desenvolvimiento. Abordaremos la espacialización de la violencia en el proyecto neoliberal siempre considerando las continuidades y rompimientos con sus configuraciones precedentes. 
Las violencias específicas que marcan las prácticas y experiencias en las ciudades contemporáneas en general son resultado de los procesos de reestructuración política y económica del capitalismo tardío neoliberal, pero a la vez representan una de sus condiciones de realización. Así, la tesis central es que el orden neoliberal se sostiene y se proyecta en una relación dialéctica, desde la propia violencia que reproduce y dinamiza el espacio, uno de sus fundamentos protagónicos. Caracterizando de manera muy sintética a la ciudad contemporánea neoliberal, Harvey (2018) señala que

[...] puede encontrarse ahora (a menudo en aumento, y en algunos casos predominante) una concentración de empobrecimiento y desesperanza humana, desnutrición y enfermedades crónicas, infraestructuras tambaleantes o estresantes, consumo derrochador y sin sentido, degradación ecológica y excesiva contaminación, congestión, un desarrollo económico y humano aparentemente obstaculizado y, algunas veces, encarnizados conflictos sociales que van desde la violencia individualizada en las calles al crimen organizado (a menudo una forma alternativa de gobernanza urbana), desde ejercicios de control social de un Estado policial a ocasionales multitudinarios movimientos cívicos de protesta (algunas veces espontáneos) que reclaman un cambio político-económico. Para muchos, hablar de la ciudad del siglo XXI es conjurar una distópica pesadilla en la que todo lo peor del fatalmente defectuoso carácter de la humanidad se reúne en un infernal agujero de desesperación. (519-520)

La ciudad neoliberal está dominada por procesos como la privatización de bienes públicos y colectivos, la mercantilización extrema, la renta cultural y tecnológica, la imposición de derechos individuales sobre propiedades colectivas, la instauración política del miedo como elementos de sociabilidad, el hiperconsumo, la estigmatización de grupos y la distancia social, entre otros, mismos que se combinan para dar como resultado una estructura socioespacial fragmentada, altamente segregada y jerarquizada. En este sentido, Adolfo Gilly y Rina Roux (2015) señalan que el neoliberalismo representa una transformación epocal caracterizada por la intensificación de las formas de violencia sobre los subalternos como uno de los fundamentos de la praxis social, a partir de la cual se orienta y gestiona la vida económica, política y cultural. Entonces, la espacialización de la violencia debe ser considerada como una mediación estratégica en la realización concreta y reproducción de ese orden neoliberal.

En el contexto neoliberal, las formas de la violencia se intensifican en la praxis social cotidiana asociadas con las condiciones de acumulación y rentabilidad, las que son cada vez más devastadoras de los recursos culturales, históricos y ambientales de las comunidades, aunado a que requieren de mecanismos altamente coercitivos para su realización (Gilly y Roux, 2015). Al respecto, para que la coerción sea más efectiva debe presentarse en forma de consenso, interiorizarse en los sujetos, con lo que se enajena el papel de la violencia como una estructura estructurante del orden social - esto es, partiendo de la concepción de habitus, que define las acciones de los individuos situados en una realidad concreta según las representaciones de sus propias prácticas históricas-. El habitus es una estructura estructurante que constituye un 
esquema generador y organizador, tanto de las prácticas sociales como de las percepciones de las propias prácticas y de los demás. Por un lado, se ponen en relación las condiciones, y por otro se interioriza la exterioridad (Bourdieu, 2002).

La intensificación de las formas diversas de violencia en la ciudad neoliberal también representa un campo fértil de acumulación generando mercados altamente rentables, como el de seguridad y las economías informales e ilegales (Capron y Zamorano, 2010). Lo anterior implica un desarrollo y complejización de la violencia como agencia social, ya que no sólo es la garante de las formas de mercado, o la barrera de contención para los efectos de las prácticas depredatorias del capital postfordista hipermercantilizado, sino que su propia realización implica una forma de valorización del capital. La violencia se abre como un campo de acumulación a partir de la subordinación material y simbólica de los sujetos.

Para Sayak Valencia (2010), en las ciudades de países periféricos ${ }^{2}$ el neoliberalismo existente es una forma de capitalismo gore, donde la vida económica, sociopolítica y simbólica cultural están marcadas por la necropolítica, ${ }^{3}$ y las violencias paralelas y complementarias generadas por el estado y los grupos narcotraficantes o del crimen organizado en general colocan la vida de las personas, su cuidado, su regulación y su libertad como objetivos del mercado. En este panorama, se pueden identificar los vínculos de retroalimentación entre las transformaciones de la vida urbana y la violencia. La ciudad se fragmenta, los barrios se cercan, se multiplican las "otredades", las estigmatizaciones sociales se amplían y profundizan (Janoschka, 2016), y el miedo sustituye al conflicto social como motor de la vida pública (Pansters y Castillo, 2007). La razón neoliberal afirma a la violencia como vector protagónico en todo el espectro social, marcando la manera de realización de las desigualdades productiva (económica) y reproductiva (política y cultural).

Bajo esta línea argumentativa se plantea el desarrollo de miradas teóricas y metodológicas de las condiciones de realización espacial de la violencia y sus impactos en la vida cotidiana en la ciudad neoliberal, haciendo énfasis en su carácter multidimensional y multiescalar. En ese sentido, se requiere superar la geografía descriptiva limitada a los análisis de distribución y localización de los actos de violencia, así como transcender las aproximaciones que buscan identificar relaciones causa-efecto entre ciertas características espaciales y la violencia. Esta propuesta se dirige a la aprehensión y comprensión de la dimensión espacial de la violencia en términos de su relación dialéctica y mutuamente constitutiva entre las condiciones y mecanismos de realización y sus expresiones y finalidades. Se asume como base de discusión el enfoque histórico geográfico materialista (Harvey, 2018), pero no en sus formas ortodoxas, sino desde los principios y argumentos que permiten ponerlo en diálogo y debate con propuestas

\footnotetext{
${ }^{2}$ En su estudio desarrolla una problemática concreta en Tijuana, México.

${ }^{3}$ Concepto que Mbembe (2011) deriva de la conceptualización de biopolítica foucaultiana y que refiere al ejercicio de poder como gestión social para determinar quién debe vivir y quién debe morir. Se trata de una regulación de la vida a través del poder de la muerte.
} 
postestructuralistas (Moebius, 2012). Por supuesto que esto entraña riesgos teóricos, pero la intención no es establecer tesis definitivas ni absolutas; más bien, lo que se quiere es abonar en la apertura de debates conceptuales que amplíen la miradas analíticas y estrategias metodológicas sobre la violencia, colocando las posibles contradicciones en movimiento para intentar fortalecer la reflexión.

Esta mirada geográfica a la violencia en la ciudad neoliberal desde el diálogo conceptual no implica eliminar del análisis las concreciones empíricas específicas, sino todo lo contrario: se trata de una propuesta teórica para comprenderlas y para imaginar las formas de intervención. Así, se trata de reconocer que el quehacer geográfico se relaciona íntimamente con el ejercicio del poder y que puede transformarse en un cuestionamiento al mismo, abriendo caminos a diversas formas de resistencias y alteridades (Raffestin, 2015). Antes de abordar el esquema comprensivo sobre la espacialización de la violencia se señala, a manera de antecedente, la historia de la geografía en relación con las propuestas de estudio sobre la violencia - de manera más específica, sobre la criminalidad, la inseguridad y el miedo, cuyos alcances y limitaciones son fundamentales para construir una genealogía crítica sobre la violencia desde la disciplina- A continuación, se contextualiza el desarrollo de dos aspectos de discusión orientados a la articulación del esquema objetivo.

El primero tiene que ver con el peso que tuvo dentro de la geografía urbana la escuela cartográfica de criminología, la cual buscó establecer relaciones causa-efecto a partir de la distribución de las variables territorializadas (Hernando, 2006; Lahosa, 2002), pretendiendo mapear las anomalías y patologías sociales para encontrar patrones de localización y distribución del crimen en las diferentes zonas de la ciudad bajo una perspectiva de ecología humana. Con la revolución neopositivista se pretendió trascender los límites descriptivos de la distribución cartográfica para hacer énfasis en las explicaciones de los fenómenos de la inseguridad y la criminalidad por medio de modelos de análisis espacial basados en regularidades estadísticas de todo tipo de variables, directas e indirectas, dependientes e independientes, respecto a los diferentes tipos de crimen (Lahosa, 2002). Y si bien estas aproximaciones permiten acercarse al estudio de las expresiones de la violencia directa, la espacialidad queda reducida a su forma absoluta, cartesiana, como un escenario donde lo importante son las relaciones de localización y distribución de los actos violentos, derivando en una clasificación de los espacios de acuerdo con una gradación cuantitativa diferenciada de la violencia, desplegándose un enfoque funcionalista que encapsula a la violencia como respuesta (Arteaga, 2004).

El segundo aspecto se refiere a las aproximaciones a la violencia desde la intersubjetividad espacial que se han propuesto desde las geografías humanísticas y posmodernas, las cuales estudian las formas en que se construyen en el imaginario socioespacial las diferentes experiencias y percepciones de miedo, inseguridad, terror, entre otros, y cómo éstas impactan en las prácticas cotidianas de los sujetos en su uso, apropiación y disputa de los diferentes lugares. Estas perspectivas dirigen la atención hacia los aspectos cualitativos de la violencia, de cómo las representaciones figuran nuestras 
experiencias individuales y colectivas, abriendo la mirada interpretativa a pensar los etiquetados y estigmas socioespaciales como modos altamente significativos de violencia. Al respecto, Laia Oliver-Frauca (2006) menciona que la distribución de los miedos urbanos son una forma de reforzar las asimetrías del poder y control de las disidencias existentes en una sociedad. A pesar de que estos abordajes buscan identificar la instrumentalización política del miedo como una forma de violencia, para el esquema que se quiere articular esto no es suficiente, ya que se pretende analizar el carácter productivo de la violencia, sí en lo simbólico, pero también en lo material, identificando sus condiciones objetivas y subjetivas de realización.

Se plantea la necesidad de desplegar una geografía que permita abordar con imaginación y con profundo compromiso los modos de interacción entre las dimensiones y ámbitos de las violencias y la reproducción de las prácticas espaciales cotidianas originadas por muy diversas formas de miedo, terror, precarización, humillación y un largo etcétera que expresa la dominación en sus múltiples facetas. Para esto, se busca desplegar un esquema comprensivo desde las bases teórico-metodológicas del desarrollo geográfico desigual (Brenner, 2017; Smith, 2008: Harvey, 2007; Janoschka, 2016), que permita visibilizar los fundamentos espaciales de la violencia urbana neoliberal.

\section{Producción de espacio y violencia estructural: fundamentos del esquema}

El punto de partida del esquema comprensivo lo representa la propuesta lefevbriana de la producción del espacio como un proceso que apela tanto a las condiciones materiales como ideológicas de la vida social. En este sentido, la propia acción de la reproducción de la vida social implica una continua producción de espacio (Alessandri, 2008). El espacio es una instancia dinámica en permanente estructuración a partir de la cual se organiza y se reproducen las otras instancias sociales, proceso que, a su vez, representa la condición de realización del propio espacio. Se trata de un producto-productor (Lefebvre, 2013). En complemento, los significados sociales que se asignan a los espacios derivan de su práctica material, y ésta es resultado de dichas significaciones articuladas como imaginarios colectivos que se constituyen como representaciones dominantes. Así, el espacio significa la objetivación de las relaciones sociales de reproducción, cuya representación simbólica es intersubjetiva (De Souza, 1998).

En esta perspectiva se recuperan los tres momentos de la producción espacial que se constituyen como claves metodológicas (Lefebvre, 1976): 1) el espacio percibido, referente a la experiencia de las formas cotidianas de uso y apropiación del espacio — se incluyen las interacciones físico materiales -; 2) espacio concebido o representación del espacio, que es la racionalización simbólica del espacio que se proyecta desde el poder como forma de hacer legibles y, por lo tanto, orientar las prácticas 
espaciales — son el momento de la dominación, de significación de los espacios desde y para el ejercicio de poder-; y 3) espacios imaginados, que son los que corresponden a invenciones simbólicas por fuera o contra dominantes, abriendo la posibilidad de prácticas espaciales diferentes a las proyectadas por la racionalidad del poder.

Derivado de lo anterior, se puede identificar que el espacio juega un papel estratégico en la reproducción de cualquier proyecto de reproducción social. Alessandri (2008) dice que "el lugar es construido como condición para la producción y para la vida, y al ser construidas estas condiciones producen un espacio jerarquizado, diferenciado, dividido, contradictorio que se consubstancia como un modo de vida dado, como formas de relacionamiento, como ritmos cotidianos, como ideología, religión y, fundamentalmente como modo de lucha" (170). El espacio no es desigual como resultado o expresión, sino como condición de reproducción (Smith, 2008), significando esta desigualdad un eje estratégico de estructuración del orden social. La producción de espacio dentro de las geografías del capitalismo es la expresión de un desarrollo intrínsecamente, y necesariamente, desigual. En esta dirección el desarrollo geográfico desigual es la condición resultante de la continua acumulación de diferencias sociales que son instrumentalizadas como condiciones desiguales de producción y reproducción, por lo que representa el eje rearticulador de los paisajes fragmentados de capitalismo (Brenner, 2017; Smith, 2008). Se trata de la expresión de "la distribución profundamente polarizada de los activos socioeconómicos, las formas de influencia geopolítica, la hegemonía ideológica, y las condiciones de la vida cotidiana, no solo entre las distintas poblaciones, sino también entre espacios posicionados diferencialmente en el seno del sistema global capitalista" (Brenner, 2017: 199). De esta manera se puede señalar que el desarrollo geográfico desigual es la síntesis de las formas diferenciadas del lugar, de la violencia en las geografías del neoliberalismo.

El otro pilar del esquema es la conceptualización de la violencia en su dimensión estructural u objetiva. Al respecto, Žižek (2009) explica que la violencia puede ser dislocada en tres dimensiones: sistémica objetiva (entendida como estructural), simbólica, y subjetiva (que también puede ser planteada como directa), siendo las dos primeras las que sostienen a la tercera, pero quedan invisibilizadas y el foco de atención se dirige a los resultados, expresiones y manifestaciones de la violencia subjetiva. De manera básica puede considerarse que la violencia es el uso consciente de fuerza que se aplica de otros, sobre otros, de manera directa o indirecta, para imponer un comportamiento contrario a su voluntad, negando su condición de sujeto libre (Echeverría, 2010), lo cual altera la legalidad del conjunto social.

Sánchez Vázquez (2003) indica que "el cuerpo es el objeto primero y directo de la violencia, aun cuando, en rigor, ésta no apunta en última instancia al hombre como ser meramente natural, sino como un ser social y constante" (452), por lo que la violencia implica una instrumentalización de los cuerpos individuales que tiene como finalidad impactar o alterar en el colectivo, en el conjunto social. Esta violencia, que se puede señalar como estructural por su carácter productivo dentro de la praxis social, es una 
estrategia fundamental para la resolución continua de "la contradicción que hay entre la coherencia 'natural' del mundo de la vida, la 'lógica' del valor de uso, y la coherencia capitalista del mismo, la 'lógica' de valorización del valor; la violencia somete o subordina sistemáticamente la primera de esas coherencias o 'lógicas' a la segunda" (Echeverría, 2010: 114).

De esta manera, se puede establecer que la violencia estructural es el conjunto de acciones coercitivas que se aplican sobre personas, grupos de personas o instituciones con la finalidad de imponer o mantener un modo específico de producción y reproducción, es decir, para establecer, ampliar y dar viabilidad a formas de acumulación y de regulación social. Se trata de un modo de generar y concentrar ganancias que pasan por la subordinación material y simbólica de los cuerpos, tanto en su condición individual como colectiva, así como de la producción de imaginarios colectivos donde la propia violencia estructural es invisibilizada como estrategia de normalización y naturalización. En este camino, las formas de violencia directa son representadas como independientes a la estructural, articulando un proceso de enajenación fundamental como legitimador del orden social de clase.

Para abordar la violencia estructural se retoma el acercamiento metodológico de Nelson Arteaga (2004) respecto a pensar ésta en tres ámbitos de concreción: “1) la económica, abordando la producción y distribución de bienes y servicios [...] 2) la política, o más concretamente su definición y distribución de poder [...] y 3) la cultural, como forma de socialización, valorización y significación" (Arteaga, 2004: 38). Como la violencia estructural representa una mediación estratégica del desarrollo desigual, sus efectos son altamente diferenciadores, por lo que su concreción reafirma las jerarquías clase, lo cual se traduce en que, aunque esta violencia se dirige a la totalidad del grupo social, sus impactos y consecuencias dependen de la condición de clase. Esta violencia es objetiva, pero produce subjetivaciones políticas desiguales, resultando en una experiencia material y simbólica altamente diferenciada.

La violencia estructural combina las jerarquías históricas de clase, género y racismo como pertenencias que estructuran los modos de producción de los bienes materiales y simbólicos necesarios para la reproducción social, dotando de sentido las formas de sociabilidad, normando y regulando las prácticas de la vida cotidiana en sus múltiples dimensiones y escalas. Desde este enfoque sobre la violencia se establece su espacialización como la instrumentalización de una organización espacial específica que opera como mediación coercitiva para imponer una racionalidad de mercado que afirma una sociabilidad profundamente desigual y fragmentada. La espacialización de la violencia deber ser aprehendida en dos dimensiones que se yuxtaponen, cuya distinción es metodológica: 1) la sujeción enajenada de la vida cotidiana a la reproducción de las relaciones de clase; y 2) la espacialidad racionalizada que soporta y genera las condiciones de la reproducción de dicho orden de clase. La primera dimensión corresponde al momento de destrucción del capital, y la segunda al momento creativo. 


\section{Espacio y violencia: un esquema mínimo de aproximación}

La espacialidad de la violencia se concreta cuando la organización de formas y funciones del espacio se imponen de forma coercitiva, enajenada o no, en la vida cotidiana como instrumento de acumulación y control social, es decir, cuando la reproducción del espacio opera como mediación encaminada a resolver la contradicción entre capital y vida a favor del primero. En la producción espacial de la violencia, la organización espacial es un recurso constitutivo del desarrollo desigual y de dominación en un orden social de clase. La reproducción de los espacios condiciona la praxis creativa de los humanos favoreciendo una praxis repetitiva cuya única finalidad es la acumulación; es decir, la violencia estructural opera como objetivación de "la enloquecida y autoestimulante circulación del capital, cuyo rumbo solipsista de partenogénesis alcanza su apogeo en las metarreflexivas actuales acerca del futuro" (Žižek, 2009: 22). El espacio, como recurso social, se pulveriza como forma estratégica de valorización, Alessandri (2008) indica que se efectúa una apropiación privada, directa como en la acumulación por despojo o indirecta como en la renta, de un producto socialmente generado. Las formas y funciones espaciales garantizan y amplian la acumulación de medios productivos y posicionan este objetivo particular y de clase como bien común.

En el proceso de realización de la espacialización de la violencia se identifican tres mecanismos fundamentales de concreción: 1) valorización del espacio vía la acumulación por despojo; 2) rentas culturales y tecnológicas (ancladas a una espacialidad específica); y 3) dispositivos espaciales de control y disciplinamiento. De estos mecanismos deriva un discurso hegemónico que busca legitimar, o al menos normalizar, los procesos de dominación hasta llegar a la propia enajenación del espacio como producto y como recurso social. Consideramos que en la trialéctica espacial lefebvriana se realiza la yuxtaposición de estos tres mecanismos con base en las condiciones históricogeográficas específicas, las que derivan en una organización espacial que representa la concreción de la racionalidad neoliberal de mercado y de un orden de clase, aspectos que a su vez significan la condición de su propia reproducción. La espacialización de la violencia se realiza en la totalidad de los espacios, pero se expresa de manera diferenciada; se trata de un proceso homogéneo que se concreta de forma heterogénea.

La violencia implica la anulación de los recursos de la reproducción social y produce un espacio-tiempo homogéneo vacío, ya sea por desplazamiento o por eliminación, acorde con las necesidades de acumulación, derivando en la espacialidad social unidimensional (Marcuse, 1968). Chatterjee (2008) también plantea la característica del espacio-tiempo de la modernidad capitalista como tiempo homogéneo vacío. Desde este planteamiento, los espacios homogéneos vacíos representarían lo que Foucault (2000) indica como una "tecnología de poder que tiene como objeto y objetivo la vida" (229), apropiarse y controlar las vidas. Los dispositivos espaciales de control y disciplinamiento pueden articularse en enclaves de violencia directa que se instrumentalizan como medio para amedrentar y controlar a la población, ya sea con la intervención directa de fuerzas estatales, en el caso de la militarización o los estados policiacos. Pero 
en los enclaves de violencia extrema donde, por un lado, hay un abandono del estado $\mathrm{y}$, por otro lado, una desintegración social, sin movilización por demandas colectivas, ocurre lo que Wacquant (2007) denomina desertificación organizacional (214). Se conjugan los mecanismos de espacialización de la violencia señalados, donde las formas y funciones derivadas son la manifestación de la racionalidad de mercado en el ámbito productivo y de las clases en el reproductivo.

\section{Espacialización de la violencia: neoliberalismo y espacio público}

El neoliberalismo es un proyecto político, económico y social que tiene como parte de sus objetivos centrales restablecer el poder de clase, ampliar la dominación de la racionalidad de mercado y fortalecer las dinámicas de acumulación y condiciones de rentabilidad, recentralizando y reconcentrando las riquezas sociales (Theodore y Brenner, 2017). De acuerdo con Gilly (2002), el neoliberalismo se sustenta en cuatro ejes: flexibilización, desregulación, despojo y atomización, a través de los cuales se expande la dominación del capital. Como todo proyecto civilizatorio, el neoliberalismo se despliega espacialmente como condición de reproducción, por lo que la ciudad reafirma su posición de lugar privilegiado de la racionalidad del capitalismo tardío. Así, la urbanización neoliberal ha implicado que "todas las características destructivas del desarrollismo fueron llevadas al extremo: segregación, motorización, verticalización, control social, pérdida de forma, desaparición del límite urbano; la ciudad era más que nunca concentración de poder e instrumento de acumulación del capital." (Amorós, 2008: s. p.).

El espacio público, como bien común sustancial de la ciudad (Lefebvre, 1976), es disputado entre su reproducción como valorización del capital y su uso para la realización de la vida social. Por una parte, opera como una forma de concreción de la violencia estructural, ya que implica formas de valorización del espacio, de rentas culturales y modos de control y disciplinamiento. Por otra parte, el espacio público puede significar la resistencia social, contraponerse al poder; por ello es intrínsecamente conflictivo y contradictorio:

En términos de Lefebvre [...], el espacio público está controlado por el gobierno u otras instituciones, su uso lo define como representación del espacio. El espacio público tal como se accede y se utiliza por los diversos grupos sociales se denomina espacio representacional. Esta distinción importante llama la atención a la diferencia entre el estatus "oficial" de un espacio y la capacidad real de varios individuos y grupos para usarlo [...]. En Lefebvre, esta dicotomía insinúa la impugnación subyacente de todo espacio público en la medida en que se reconoce que el espacio "no es simplemente un recipiente vacío esperando que algo suceda, sino que se construye por medio de las relaciones y los procesos sociales" [...] [En consecuencia], el espacio público puede concebirse como el producto de dos ideologías en competencia [...]. Por un lado, desde el enfoque de orden se visualiza al espacio público como el sitio 
de control y se asocia, típicamente, con la tradición autoritaria donde el panóptico y la represión se utilizan para mantener el orden y la estabilidad. Este enfoque rivaliza con otra perspectiva que conceptualiza al espacio público como el lugar donde los sin voz puede hacer que sus demandas sean vistas y escuchadas, como un medio para la disputa del poder, el espacio en el que la identidad se construye se cosifica y se cuestiona. (Springer, 2009: 140)

Este proyecto de regulación social del espacio se articula con base en la histórica acumulación de desigualdades, antagonismo y formas de violencia; sus características específicas se codeterminan por sus contextos históricos y geográficos. En la ciudad fragmentaria neoliberal, los espacios públicos son ejes estratégicos de proyección y realización de la violencia estructural, pero también de sus formas de interpelación como contra-interpelación del poder; "la violencia a menudo se entiende como un resultado de los intentos de imponer una visión 'ordenada' del espacio público que se origina 'desde arriba' y como un acto de resistencia 'desde abajo' por parte de aquellos que buscan espacios democráticos radicales de interacción 'espontánea'” (Springer, 2019:118).

El espacio público homogéneo y vacío representa a la violencia y el autoritarismo como las formas de gobierno territorial del neoliberalismo, con la racionalidad particular del mercado, impuesta como universal, expulsando otras posibilidades, vaciando ese espacio como posibilidad de política desde abajo o subalterna. Duhau y Giglia (2008) indican que dentro del proyecto neoliberal el espacio público experimenta una

creciente segmentación social, una restricción de los grados de apertura (tanto material como simbólica) y resultan sujetos a diversas formas de interdicción y exclusión y cuando la jurisdicción pública democráticamente regulada y acotada es sustituida por corporaciones privadas o grupos de ciudadanos en tanto propietarios privados; sin duda la publicidad de los espacios de uso colectivo retrocede en la misma medida. (49)

El espacio público, bajo el disfraz de diversidad cultural, de integración social, de democracia política, significa una forma de realización del valor, directa o indirectamente, ya sea por medio de la mercantilización o privatización a partir de la renta diferencial, además de constituirse como un medio de realización del discurso del orden y, por lo tanto, como eje de estabilidad del proyecto neoliberal (Springer, 2009). En esta dirección destacan las dinámicas de tematización y "disneyficación" del espacio público (Boyer, 2004), como estrategias del regreso del capital a ciertas calles, su recuperación como espacio privilegiado de acumulación y renta (Smith, 2008) y acompañado de formas más intensas de vigilancia, control y disciplinamiento. Las formas de antagonismo y el disenso político son sustituidas por la homogenización plana de un espacio hipervigilado y mercantilizado, Springer (2009) agrega que:

El espacio público es idealmente, desde el punto de vista inmediato, un medio que permite la autorrepresentación incorporada. Así, cuando se priva del espacio público, 
los individuos no pueden situar su autorrepresentación existencialmente. En consecuencia, la impugnación es inadmisible y la autorrepresentación se vuelve (casi) incorpórea en forma. Cuando el péndulo oscila demasiado en la dirección de lo privado (es decir, hacia la vista ordenada), la privatización resultante del espacio público tiene dos consecuencias aparentes: (1) la erosión de la voluntad individual que resulta en una población sumisa, presumiblemente el efecto deseado de la vista ordenada; o (2) la materialización de "transcripciones ocultas" y estallidos violentos ocasionales contra quienes oprimen el espacio público, representando una rebelión contra una cruel relación dominante-subordinado [...], y el efecto no deseado de la vista ordenada. Donde la marginación, la exclusión y vulnerabilidad genera miedo, la violencia se convierte en una de las únicas formas practicables de autorrepresentación pública [...]. (141)

Así, las formas de realización de la violencia estructural en los espacios públicos también se efectúan en la gestión diferenciada de la seguridad, haciendo que las condiciones que resguardan los recursos económicos y sociales de las élites se sostengan a partir de la subordinación de los múltiples otros grupos sociales. Y es en este contexto donde la reproducción del espacio público vaciado y homogéneo opera como resultado y condición de realización de ese orden regulatorio y de control. Así, el miedo como instrumentalización política (Corey, 2009) se torna concreto en la forma urbana, remodelando y orientando la experiencia de los espacios públicos, desplegándose como aceptación de restricciones y modos de control en nombre de un supuesto bien común, cuando no se trata más que del mantenimiento de un orden jerarquizado con base en desigualdades de clase, género y el racismo. El miedo como estratagema de dominación desempeña un papel protagónico en la reestructuración interna de las ciudades bajo el proyecto neoliberal. Éste significa un instrumento cada vez con mayor importancia en los procesos de acumulación, traduciéndose en una mercantilización de la seguridad (Grey y Wyly, 2007), misma que encuentra en los espacios públicos un campo privilegiado de despliegue a la vez que reafirma el poder de clase. En este sentido se puede plantear que el miedo es operacionalizado como cuña de normalización de la excepción.

En ciudades como la Ciudad de México se aprecia un incremento en los dispositivos físicos y tecnológicos de vigilancia en los espacios públicos, que en nombre de la seguridad representan formas de disciplinamiento y segregación socioespacial. Así muchas colonias cierran sus calles y controlan el acceso, otros fraccionamientos nacen cercados, y en las calles y plazas se colocan videocámaras, privadas y públicas, y barreras que ordenan la movilidad. En esta dirección,

Las zonas públicas expresamente vigiladas se convierten en espacios contradictorios, en sitios aparentemente abiertos a todo el mundo, pero que en realidad son exclusivos [...]. La experiencia de estos espacios se convierte en cierto modo ideal, gracias a la ausencia de personas y actividades no deseadas por parte de los colectivos que "legítimamente" controlan y se apropian de los entornos vigilados; mientras que los individuos no admitidos se ven marginados y a la utilización forzosa de los espacios públicos restantes [...]. (Oliver-Frauca, 2006: 372) 
Por otro lado, los espacios públicos también han significado el eje de realización de movimientos sociales y de puesta en marcha de proyectos antagónicos al proyecto neoliberal, representado la base espacial de la democracia radical (Springer, 2019), buscando abrir caminos la realización de la comunidad política concreta. Son la posibilidad de los espacios negativos, pensados como

\begin{abstract}
espacios de libertad como territorios recuperados, como espacios de recreación y de inventiva. Como espacios deliberadamente generados en contraposición a los de los poderosos, construidos en la lucha, en el rechazo y la resistencia; como universos propios dentro del Universo, contradictorio, del poder. Es decir, el espacio de libertad no es el que el sistema de dominación deja por descuido, abandonado en el camino, sino el que los subalternos le arrebatan y reconstruyen; el espacio de libertad es lo que la voluntad política de las resistencias es capaz de crear, es un espacio de rebelión. (Ceceña, 2004: 44)
\end{abstract}

La lógica militar que impregna las formas de gobierno del territorio en esta etapa de neoliberalización refuerzan la creciente percepción de inseguridad y vulnerabilidad urbana que impulsa la extensión y al mismo tiempo la aceptación de estrategias de terror dirigidas a la eliminación de toda agencia que no se alinee con la forma social dominante, constituyendo ciudades del terror, en las cuales se exacerban las complejidades de las interacciones socio culturales, intensificando las tensiones de identidad y alteridad (Grey y Wyly, 2007). En las ciudades donde la lucha contra el terrorismo no forma parte protagónica de la agenda política, como las de México, la lógica militar igualmente puede estar presente en las estrategias de control urbano, si contraponen y buscar antagonizar a los habitantes por medio de calcificaciones culturales e identitarias, en términos biopolíticos, como dispositivos de poder sobre el cuerpo, de tal manera que hay una continua construcción de otros dirigida a fragmentar, vigilar, disciplinar y regular la vida social.

Las políticas de seguridad que tienen como objetivo al espacio público representan formas de apropiación o control sobre la población, ya que en nombre de la seguridad se ordena y regulan las formas de uso y disfrute del mismo. La seguridad, como un bien público de acceso diferenciado, se constituye como uno de los elementos centrales para ordenar la vida urbana y separar a las clases. De esta manera la ciudad se fractura también en relación con la seguridad. Este proceso es muy similar a lo que significaron las políticas de higiene urbana a finales del siglo XIX y principios del XX.

En el ámbito cultural, el proyecto neoliberal ha reforzado los procesos de estigmatización y de distancia social, reelaborando múltiples otredades como base de las identidades colectivas, lo cual ha incrementado las formas de individualización y atomización que favorecen el hiperconsumo como fundamento de la socialización. Los espacios públicos anclan valores neoconservadores que privilegian las diferencias de clase y criminalizan la pobreza como medio para legitimar y demandar acciones de control y vigilancia social por parte de los gobiernos. En el mapa social de las ciudades bajo el proyecto neoliberal, los espacios públicos se han convertido en 
áreas obscuras donde el discurso político ha descargado un imaginario social de fobias y miedos que presionan para su disciplinamiento y privatización. El tipo de ciudad que se produce genera formas de interacción social y política que intensifican las diferencias entre clases y los procesos de separación, diferenciación y jerarquización de la población. Se genera una segmentación social de lo público (Borja, 2003) donde las clases altas y medias buscan lugares de convivencia entre iguales (normalmente de propiedad o gestión privada), separándose de los otros, de las multitudes pauperizadas por medio de mecanismos de mercado (accesibilidad y precios), representativos (modos de vestir, de consumir, de comportarse) y físicos (sistemas de vigilancia que operan con principios sociales de discriminación), dejando para las clases bajas los lugares deteriorados y en peores condiciones.

Una forma extrema de realización de los espacios homogéneos vacíos es los “espacios de muerte", los cuales, explica Oslender (2007), se tratan de la conformación de paisajes articulados por signos visibles de la violencia directa que se utilizan como estrategias de comunicación para crear miedo y generar desplazamientos y expulsiones, y en estos "espacios de muerte" los estados desempeñan un papel fundamental, a veces de manera directa otras por omisión intencionada. El propio autor agrega:

[...] estos paisajes de miedo se pueden "leer" a través de sus huellas. Ellos también se manifiestan en lo que se puede considerar como "espacios vacíos", como pueblos abandonados por sus habitantes que huyen de persecuciones y masacres. Aunque las personas a veces regresan a sus casas después de haber sido desplazadas, la sensación del terror y el miedo producidos quedan grabados en la imaginación de las personas y en la tierra. (Oslender, 2007: 120)

Los espacios públicos, en su forma homogénea y vacía, materializan la violencia cuyo corolario es la racionalidad neoliberal, donde las víctimas no tienen propiedad ni lugar en el mercado, son representados como los transgresores del espacio público y los perpetradores de la violencia (Springer, 2009). Sin embargo, la realidad la subordinación y la pauperización son los medios de realización del orden desigual, jerárquico y disciplinario y el espacio público justamente establece un esquema de aproximación de su papel dentro de la destrucción creativa del capital, de sus posibilidades como espacio de representación, de articulación de la subalternidad.

El espacio público es un campo estratégico de disputa, donde la violencia se realiza con su homogeneización y vaciamiento con dispositivos de control desenvueltos en la performatividad de los sujetos, que se desdobla en una diferenciación del reconocimiento social desde el poder que marca qué vidas merecen la pena ser vividas y cuáles no (Butler, 2009). Se diferencía y ordena a los cuerpos de acuerdo con criterios de clase, de racialización, de género e identitarios. Frente a esto, las contradicciones del poder también se abren paso en los espacios públicos, buscando la articulación de una democracia radical que cuestione tanto a los capitales nacionales y trasnacionales como a las propias élites (Springer, 2019). El espacio público neoliberal produce un 
reconocimiento selectivo de las diferentes formas de sujetos sociales, de los recursos materiales y simbólicos que pueden usar unos y cuáles otros, alienando el lugar social de las colectividades y de los individuos.

\section{Conclusiones}

El esquema comprensivo propuesto permite analizar las formas concretas del asalto del espacio público por parte del neoliberalismo, identificando la realización del desarrollo desigual en los ámbitos económico, político y cultural. En el primero se visibiliza una estrategia de recentralización de capital vía las renovaciones y recuperaciones urbanas que abren caminos de privatización, mercantilización y rentas culturales y tecnológicas, colocando al propio espacio público como un bien escaso sujeto a las reglas de mercado, de tal forma que el valor de uso del espacio se subordina a su valor de cambio. Así, el discurso de integración cultural y de diversidad multicultural se instrumentaliza como medio de valorización.

En lo que se refiere a la esfera política, los espacios públicos anclan un imaginario colectivo que neutraliza los conflictos en los cuales la distancia social y el miedo se conforman como ejes protagónicos de la sociabilidad. Este miedo, como idea política, ha colocado en las representaciones sociales al espacio público como el lugar predilecto del crimen, de la anomia social, desarticulando procesos de solidaridad y convivencia. Así en el espacio público se extiende, se disputa y se legitima el uso de la violencia directa estatal, colocando un velo sobre los procesos de despojo y control que se articulan en su reproducción. En esta dirección, De Souza (2008) explica que en las ciudades del sur global (como Río de Janeiro, Ciudad de México, Johannesburgo, Medellín, entre otras ${ }^{4}$ ), la experiencia práctica del miedo constituye un "condicionamiento de las relaciones sociales y de modelaje del espacio" (2008: 13). que provoca formas específicas de producir, habitar y apropiarse de la propia ciudad, por lo que éstas despliegan una gubernamentalidad basada en el miedo, por lo que pueden ser consideradas como fobópolis.

Los espacios públicos en la ciudad neoliberal constituyen uno de los ejes de realización espacial de la violencia estructural, ya que son un elemento de valorización, fundamentalmente a través de la generación de rentas diferenciales que permiten la captación de plusvalía por particulares, pero también representan un dispositivo de regulación social a la vez que ancla y amplifica un discurso de supuesta neutralidad y normalización que invisibiliza los procesos de dominación. En los espacios públicos se despliegan los mecanismos de vigilancia y control corporal que articulan las formas de gubernamentalidad. Así, la seguridad se posiciona como un recurso de acceso diferenciado que refuerza las desigualdades sociales a la vez que permite contener o gestionar

\footnotetext{
${ }^{4}$ De manera específica en su investigación desarrolla el caso de Rio de Janeiro.
} 
las protestas y disidencias al proyecto neoliberal. La importancia del espacio público en la conformación de movimientos sociales y como eje de demandas de distinto signo es una de las claves para comprender porque el revanchismo neoliberal ha tenido en el espacio público uno de sus objetivos primordiales.

En síntesis, se puede señalar que el esquema comprensivo de la espacialidad de la violencia debe desdoblarse en el análisis de los espacios homogéneos vacíos como ejes de una ciudad "compartimentada, segregada, de guetos de ricos y pobres, de zonas industriales y de campus universitarios, de centros abandonados y de suburbios chaletizados que es producto de la agorafobia urbana, del temor al espacio público" (Borja, 2003: 206). Así, desde la espacialidad de la violencia, se debe poder hacer un recorrido analítico sobre las experiencias materiales y simbólicas de la depredación, despojo y humillaciones que caracterizan a las geografías contemporáneas del capitalismo (Gregory y Pred, 2007), para poder dar cuenta de las formas y funciones de la estructura espacial del urbanismo neoliberal fragmentario como condición y expresión del desarrollo desigual. La realización de la violencia en los espacios homogéneos vacíos implica el despliegue de una serie de mecanismos y estrategias que buscan dar sentido a un mundo estructurado por la desigualdad, misma que se presenta como la vida cotidiana real donde actuamos, pensamos, hablamos, es decir, donde nos conformamos como sujetos históricos concretos. Los espacios vacíos homogéneos se desdoblan como las topologías de la violencia neoliberal.

\section{Referencias bibliográficas}

Alessandri, Ana. (2008). A (re)producao do espaco urbano. Sao Paulo: EDUSP.

Amorós, Miguel. (2008) "Urbanismo y Orden" (Conferencia pronunciada el 20 de diciembre de 2003 en el Ateneu Llibertari de El Cabanyal, Valencia). Periferies Urbanes-Grup de Treball de l'Institut Català d'Antropologia. Disponible en http://periferiesurbanes.org/wp-content/uploads/2011/03/AMOROS2003UrbanismoOrden.pdf

Arteaga, Nelson. (2004). En busca de la legitimidad: violencia y populismo punitivo en México, 1990-2000. México: UACM.

BorJa, Jordi. (2003). La ciudad conquistada. España: Editorial Alianza.

BrenNER, Neil. (2017). "Mil hojas: notas sobre las geografías del desarrollo espacial desigual”. En Álvaro Sevilla Buitrago (Ed.), Neil Brenner. Teoría urbana crítica y politicas de escala. Barcelona: Icaria, 195-233.

Bourdieu, Pierre. (2002). La distinción. Criterio y bases sociales del gusto. México: Taurus.

Boyer, Christine. (2004). "Ciudades en venta: la comercialización de la historia en el South Street Seaport”. En Sorkin, Michael (ed), Variaciones sobre un parque temático. Barcelona: GG Mixta. 205-230. 
Butler, Judith. (2009). "Performatividad, precariedad y políticas sexuales". AIBR. Revista de Antropología Iberoamericana, 4(3), 321-336.

CApron, Guémola; Zamorano, Claudia. (2010). "Retos de la privatización de la seguridad". Ciudades, (86), 2-14.

Ceceña, Ana. (2004). "Hacia la construcción de una hegemonía sin límites". En Ana Ceceña (Coord.), Hegemonías y emancipaciones en el siglo XXI. Buenos Aires: CLACSO. 37-58.

ChatterJee, Partha. (2008). La nación en el tiempo heterogéneo y otros estudios subalternos. Buenos Aires: Siglo XXI.

Corey, Robin. (2009). El miedo. Historia de una idea política. México: Fondo de Cultura Económica.

De SouzA, Marcelo. (1998). “Algunas notas sobre la importancia del espacio para el desenvolvimiento social”. En Graciela Uribe (Comp.), Cuaderno de geografía brasileña. México D. F.: Centro de Investigación Científica "Ing. Jorge L: Tamaño". 69-93.

De Souza, Marcelo. (2008). Fobópole. O medo generalizado e a militarizacao da questao urbana. Río de Janeiro: Bertrand.

DuHAu, Emilio; Giglia, Ángela. (2008). Las reglas del desorden. Habitar la metrópoli. México: Siglo XXI; UAM Azcapotzalco.

EcheVerría, Bolívar. (2010). Valor de uso y utopía. México: Siglo XXI.

Foucault, Michel. (2000). Defender la sociedad. México: Fondo de Cultura Económica.

GiLLY, Adolfo. (2002). El siglo del relámpago: Siete ensayos sobre el siglo XX. México: Ítaca; La Jornada Ediciones.

Gilly, Adolfo; Roux, Rina. (2015). El tiempo del despojo. México: Ítaca.

Gray, Mitchell; Wyly, Elvin. (2007). “The Terror City Hypothesis”. En Derek Gregory y Allan Pred (Eds.), Violent Geographies. Fear, Terror, and Political Violence. Nueva York: Routledge. 329-348.

Gregory, Derek; Pred, Allan (Eds.). (2007). Violent Geographies. Fear, Terror, and Political Violence. Nueva York: Routledge.

Harvey, David. (2007). Espacios del capital. Hacia una geografía crítica. Madrid: Akal.

Harvey, David. (2013). Ciudades Rebeldes. Del derecho a la ciudad a la revolución urbana. Madrid: Akal.

Harvey, David. (2018). Justicia, naturaleza y la geografía de la diferencia. Madrid: Traficante de Sueños.

Hernando, Felipe. (2006). "Geografía y violencia urbana”. En Daniel Hiernaux y Alicia Lindón (Comp.), Tratado de geografia humana. México: Antrophos. 506535.

JANOSCHKA, Michael. (2016). “Gentrificación, desplazamiento, desposesión: procesos urbanos claves en América Latina”. Revista INVI, 31(88), 27-71. http://dx.doi. org/10.4067/S0718-83582016000300002 
Lahosa, Joseph. (2002). "Delincuencia y ciudad. Hacia una reflexión geográfica comprometida". Biblio 3w: Revista Bibliográfica de Geografía y Ciencias Sociales, 7. https://www.raco.cat/index.php/Biblio3w/article/view/66389

Lefebvre, Henri. (1976). Espacio y política. Barcelona: Península.

Lefebvre, Henri. (2013). La producción de espacio. Madrid: Capitán Swing.

MARCuSE, Herbert. (1968). El hombre unidimensional. Ensayo sobre la ideología industrial avanzada. México: Editorial Joaquín Mortiz.

MBEMBE, Achille. (2011). Necropolítica. Barcelona: Melusina.

Moebius, Stephan. (2012). "Posestructuralismo y ciencias sociales". En Enrique de la

Garza y Gustavo Leyva (Eds.), Tratado de metodología de las ciencias sociales: perspectivas actuales. México: FCE-UAM. 525-566.

Oliver-Frauca, Laia. (2006). "La ciudad y el miedo". En Joan Nogué y Joan Romero (Comps.), Las otras geografias. Valencia: Tirant Lo Blanch. 369-388.

Oslender, Ulrich. (2007). "Spaces of Terror and Fear on Colombian's Pacific Coast".

En Derek Gregory y Allan Pred (Eds.), Violent Geographies. Fear, Terror, and Political Violence. Nueva York: Routledge. 111-132.

Pansters, Will; Castillo, Héctor. (2007). "Violencia e inseguridad en la ciudad de México: entre la fragmentación y la politización”. Foro Internacional, 47(3), 577615.

Raffestin, Claude. (2015). Por una geografia del poder. Zamora: El Colegio de Michoacán.

SÁnchez VÁzquez, Adolfo. (2003). Filosofía de la praxis. México: Siglo XXI.

Sмiтh, Neil. (2008). Uneven Development: Nature, Capital, and the Production of Space. Georgia: The University of Georgia Press.

Springer, Simon. (2009). "Violence, Democracy, and the Neoliberal "Order": The Contestation of Public Space in Posttransitional Cambodia". Annals of the Association of American Geographers, 99(1), 138-162. https://doi. org/10.1080/00045600802223333

SPRINGER, Simon. (2019). Las raices anarquistas de la geografia. Hacia la emancipación espacial. México: Instituto de Geografía, UNAM.

Theodore, Nikolas; Brenner, Neil. (2017). "Las ciudades y las geografías del neoliberalismo realmente existente". En Álvaro Sevilla Buitrago (Ed.), Neil Brenner. Teoría urbana crítica y políticas de escala. Barcelona: Icaria. 113-59.

Valencia, Sayak. (2010). Capitalismo Gore. Barcelona: Melusina.

WaCQUANT, Loïc. (2007). Los condenados de la ciudad. Gueto periferias y estado. Buenos Aires: Siglo XXI.

ŽıžEK, Slavoj. (2009). Sobre la violencia. Seis reflexiones marginales. España: Paidós Ibérica. 